\title{
Infantile colic, facts and fiction
}

\author{
Abdelmoneim E M Kheir
}

A retraction article was published for this article. It is available from the following link; http://www.ijponline गt/ content/40/1/9.

\section{Abstract}

Infantile colic is one of the major challenges of parenthood. It is one of the common reasons rents stek medical advice during their child's first 3 months of life. It is defined as paroxysms of crying lastin nore 3 hours a day, occurring more than 3 days in any week for 3 weeks in a healthy baby aged 2 week to $4 \mathrm{n}$. ths. Colic is a poorly understood phenomenon affecting up to $30 \%$ of babies, underlying organic causes sxcessive crying account for less than 5\%. Laboratory tests and radiological examinations are unnecessary if the infai s gaining weight normally and has a normal physical examination. Treatment is limited and d/ug eatmen has no role in management. Probiotics are now emerging as promising agents in the trea colic. Alternative medicine (Herbal tea, fennel, glucose and massage therapy) have not proved be, consistently helpful and some might even be dangerous. In conclusion infantile colic is a common of maternal distress and family disturbance, the cornerstone of management remains reassurance of plarenty, regarding the benign and self-limiting nature of the illness. There is a critical need for more evidence based treatment protocols.

Keywords: Colic, Crying, Infant, Baby

\section{Introduction and definition}

It is a behavioural syndrome characterized by cxce paroxysmal crying, that is most likely to evenings without any identifiable cause. The are so many definitions but the most widely used one is oased on the amount of crying by Wesse et al. which states that it is paroxysms of excessive cry in a otherwise healthy baby lasting more $a n 3$ nours per day, occurring $>3$ days in any week ipr $k$ s, aged 2 weeks to 4 months [1]. Rule of ee.

Colic is one of the $\mathrm{mm}$ in rea ons parents seek medical advice for the ba $_{\text {i }}$ in nis first 3-4 months of life. Those most aff ted by $\mathrm{C}$ ac are the parents. Sleepless nights and the in a ty to console a newly arrived baby cause a sreat deal $o_{1}$ stress, especially among first-time parents. To hers of infants with colic were found to be mom con ner/ about their infants' temperament and ren feel ejection compared with mothers of infants h our aic $[2,3]$.

Co $k y$ babies may be at an increased risk of abuse at the hands of exhausted and frustrated parents. Additionally, the parent may not properly bond with the child

Correspondence: moneimkheir62@hotmail.com

Department of Paediatrics, Faculty of Medicine, University of Khartoum, Khartoum, Sudan be,ause of feelings of inadequacy and anger, leading to developing behavioral problems as the child grows [4]. The term colic derives from the Greek word kolikos or kolon, it is quite characteristic, a baby who has colic often cries about the same time every day, usually in the late afternoon or evening. Colic episodes may last from a few minutes to three hours or more on any given day. The crying usually begins suddenly and for no clear reason. The baby may have a bowel movement or pass gas near the end of the colic episode. Colic crying is intense and often high pitched. The face may flush, and he or she is extremely difficult - if not impossible - to comfort. Posture changes like Curled up legs, clenched fists and tensed abdominal muscles are common during colic episodes [5,6].

\section{Epidemiology}

Internationally Colic affects $10-30 \%$ of infants worldwide. This condition is encountered in male and female neonates and infants with equal frequency. The colic syndrome is commonly observed in neonates and infants aged 2 weeks to 4 months. The incidence of colic in breastfed and bottle-fed infants is similar with no difference [7]. Increased susceptibility to recurrent abdominal pain, allergic disorders and certain psychological disorders may be seen in some babies with colic in their
C Bïomed Central

(C) 2012 Kheir; licensee BioMed Central Ltd. This is an Open Access article distributed under the terms of the Creative Commons Attribution License (http://creativecommons.org/licenses/by/2.0), which permits unrestricted use, distribution, and reproduction in any medium, provided the original work is properly cited. 
childhood. Illingworth found no association between the mother's age, parity, or pregnancy history and colic [8].

\section{Aetiology}

The cause of infantile colic remains unclear. Underlying organic causes of excessive crying must be considered during the evaluation. Organic causes account for less than 5 percent of infants presenting with excessive crying. These includes CNS causes like infantile migraine and subdural haematoma, GIT causes include constipation ,Cow's milk protein intolerance, Gastro esophageal reflux ,Lactose intolerance, Intussusception, rectal fissure, strangulated inguinal hernia. Infections like Meningitis, Otitis media, Urinary tract infection and viral illness can also mimic colic. Trauma has to be excluded in a colicky baby namely child abuse, corneal abrasions, Foreign body in the eye, fractured bone and hair tourniquet syndrome $[9,10]$.

Gastrointestinal, psychosocial, and neurodevelopmental disorders have been suggested as the cause of colic.

Gastrointestinal disorders have been implicated in colic because of the infant's leg position and grimacing during a crying spell. Excessive crying or increased gas production from colon function can result in intraluminal gas formation and aerophagia. This mechanism does not appear to be the cause of colic, however, because radiographic images taken during a crying episor ha) shown a normal gastric outline [11]. Gut horm ones as motilin also may play a causative role in Motili. is thought to cause hyperperistalsis, learing to bominal pain and colic [12].

Although studies have addressed $\mathrm{p}$ ssible psychosocial causes of colic, no evidence has bee aund in support of this mechanism. Even when licky inrants are cared for by trained occupational thelap on cry twice as long as infants without The hypothesis that colic is an early manifestatio of difficult temperament is not supported by prospectiv ongitudinal studies $[13,14]$.

Studies have gested at colic may lie at the upper end of the norma stribution of crying in infants. The fact that nost infants) utgrow colic by four months of age lends $\mathrm{su}_{\mathrm{L}}$, to a neurodevelopmental cause of colic [9].

N eph niclogic evidence suggests that exposure to gare te smoke and its metabolites may be linked to infa. e curc. Moreover, studies of the gastrointestinal systo provide corroborating evidence that smoking is linked to increased plasma and intestinal motilin levels and higher-than-average intestinal motilin levels are linked to elevated risks of infantile colic [15].

\section{Work up}

Colic is a common condition in early infancy that causes a great deal of concern. Parents and caregivers should be encouraged to document crying and fussing spells for review by the physician. A period of wellness followed by specific periods of crying is reassuring. Diagnosis is by exclusion. Further workup should be considered in infants who have frequent regurgitation of more than $28 \mathrm{~g}(1 \mathrm{oz})$, apneic or cyanotic episodes, fever, respiratory difficulties, poor weight gain, or abnormal fi dings on neurologic examination. Serial examination the infant during times of the day when the infant is 1 russy may be necessary [16-18].

Laboratory tests and radiographic e $e_{\lambda}$ inatiols usually are unnecessary if the child is gainin है eight normally and has a normal physical $\mathrm{e}$ amination $\left.{ }_{1} 19\right]$.

If the patient's stools are exc ively yatery, testing them for excess reducing su anc cinitest) may be worthwhile. If results ar positi this may be an indication of an underlying $\mathrm{A}_{\mathrm{A}}$ oblem, such as acquired (post infectious) lactose intolera. Stool may be tested for occult blood to ult ut cows milk allergy.

Mothers ofte be hat their baby's crying may be related to milk fo ula or disease which can be managed by ch ing the infant's formula from cow's milk to a soya proten $r$ casein hydrolysate formula. When a formula wa changed, mothers more frequently believed tha he cause of the problem was intrinsic to the child $(\mathrm{P}<\mathrm{C} \quad 01)$ and that their infant had had a "disease or ills" $(\mathrm{P}<0.001)$. When formula changes occurred, 26\% of mothers believed that their infants were allergic to cow milk. These beliefs may affect a mother's perceptions of her child's vulnerability [20].

\section{Treatment}

The mainstay of colic management is an acknowledgment by the physician of the difficulties the parents are facing and an inquiry into the well-being of the parents [21]. The single most effective step remains reassurance of parents regarding the benign and self-limiting nature of the illness as most of the babies improve by the age of 3 to 4 month. Drug treatment generally has no place in the management of colic, unless the history and investigations reveal gastro esophageal reflux.

Simethicone, a safe, over-the-counter drug for decreasing intraluminal gas, it is a non absorbable medication that changes the surface tension of gas bubbles, allowing them to coalesce and disperse and releasing the gas for easier expulsion. It has been promoted as an agent to decrease colicky episodes. A randomized, placebocontrolled, multicenter trial concluded that treatment with this agent produces results similar to those of placebo. The perceived improvement may be a placebo effect. Two other RCTs found no benefit for treatment with simethicone [22].

Dicyclomine hydrochloride is an anticholinergic drug that has been proven in clinical trials to be effective in the treatment of colic. However, because of serious, although 
rare, adverse effects (eg, apnea, breathing difficulty, seizures, syncope), its use cannot be recommended [23]. Cimetropium bromide, which is widely used in Italy to treat infantile colic, showed a decrease in duration of crying crises in the treated group compared with placebo. The major side effect was sleepiness; there were no reports of life-threatening events [24].

Dietary changes like eliminating cow's milk proteins is indicated only in cases of suspected intolerance to the protein (eg, positive family history, eczema, onset after the first month of life, association with other GI symptoms such as vomiting or diarrhea). In infants with suspected allergy to cow's milk protein (formula fed) a protein hydrolysate formula is indicated. Extensively hydrolyzed protein formulas may reduce colic, while partially hydrolyzed formulas should not be used in infants with colic due to cow's milk protein allergy [25].

Use of soy-based formula is not recommended because many infants allergic to cow's milk protein may also develop intolerance to soy protein. if the mother is breastfeeding, a period of elimination of allergenic foods (e.g. dairy, nuts, soy, citrus, etc.) from her diet in order to observe changes in the baby's condition. If the crying is related to a cow's milk allergy benefits are usually seen within 2-7 days [26-28].

Hill et al. suggested that a period of dietary modification with a low allergen diet and appropriate nut on I support should be considered in healthy infants $h$ colic .He also found that exclusion of all $\mathrm{H}_{\mathrm{C}}$. nic fooc from the maternal diet was associated yith a 'uction in distressed behavior among breastfe infants wit, colic presenting in the first 6 weeks of life 29,30].

In some patients, exercise-induced aphy actic reactions (EIAN) occur only when narticular food is eaten before exercise. Food-exercise con challenge may be useful in identifying 2 s tha favor exercise-induced anaphylactic reactio - in hildren with multiple fooddependent EIAn 132 , 32

Probiotics $m$ a have a sle in treatment of infantile colic. Lactobacillus uteri endogenous to the human GI tract wa found to 1)-rieve colic symptoms in breastfed infants th or e week of treatment. In a more recent stu' 50 . 'us ively breastfed colicky infants were ran$\mathrm{oml}$ assign ed to receive either $\mathrm{L}$ reuteri or placebo a. $101-1$ days. A $50 \%$ reduction in crying time from base $\mathcal{C}$ was noted in the $\mathrm{L}$ reuteri group compared with the placebo group on days 7 . The study concluded that $\mathrm{L}$ reuteri at a dose of 108 colony-forming units per day improved symptoms of infantile colic and was well tolerated and safe. Further studies are needed before this can be recommended as a routine therapy for colic in infants $[33,34]$. Recently as revised by Critch there is insufficient evidence to recommend for or against the use of probiotics or prebiotics in the management of colic [35].

\section{Alternative medicine}

Oral hypertonic glucose and sterile water were compared for treatment of colic in infants in a randomized trial. In the group receiving glucose, $30 \%$ had significantly less colic than the placebo group [36].

Herbal teas containing mixtures of chamomila vervain, licorice, fennel, and lemon balm, used ur to three times a day $(150 \mathrm{~mL}$ per dose) have been show to decrease crying in colicky infants. Given the multiplic of herbal products, the lack of standardiza $n$ of $s$ rength and dosage, and potential interferen w with rmal feeding, parents should be cautioned out their y.se $[37,38]$.

Spinal manipulation is a traditi al form of treatment practiced by chiropractors, oopa physiotherapists and other healthcare p oviders ostly (but not exclusively) to treat mus a celetal problems. Spinal manipulation can be describe $s$ the use of hands applied to the patient $\mathrm{iCO}_{\text {, }}$ orating the use of instructions and maneuvers to. ximal painless movement and exposure of the $m_{1}$ culoskeletal system. Evidence for the efficacy o nal manipulation in treating infantile colic is inconclisive. Physicians should be cautious about recommenaing spinal manipulations in infants $[39,40]$.

- thmic calming techniques are effective in calming colic babies which forms the core of the 5 Ss approach.

1. Swaddling, safe swaddling carefully avoiding overheating, covering the head, using bulky or loose blankets, and allowing the hips to be flexed [41,42].

2. Side or stomach (holding a baby on the back is the only safe position for sleep, but it is the worst position for calming a fussy baby);

3. Shhh sound (making a strong shush sound near the baby's ear $[43,44]$.

4. Swinging the baby with tiny jiggly movements (no more than 1" back and forth) always supporting the head and neck $[44,45]$

5. Sucking (Letting the baby suckle on the breast, your clean finger or a pacifier)

Numerous studies mentioned above have shown that when key components of the "5 S's" (e.g. swaddling, shushing, swinging) are used all night they can improve sleep or reduce crying; and, when the " $5 \mathrm{~S}$ 's" are done correctly and in combination, they offer significant potential to promptly reducing infant crying and promote sleep.

Remind parents about the importance of feeding a hungry baby, changing wet diapers, and comforting a baby who is cold and crying as a result of these factors. Soothing music accompanied with parental attention (including eye contact, talking, touching, rocking, walking, and playing) may be effective in some infants and is never harmful.

Encourage parents to discuss their feelings and concerns with each other to obtain support. Emphasize the 
responsibility of the whole family in the care of a baby with colic.

\section{Conclusion}

Infantile colic is a common cause of maternal distress and family disturbance, the cause remains unclear, the cornerstone of management remains reassurance of parents regarding the benign and self-limiting nature of the illness as most of the babies grow out of it by the age of 3-4 months. Investigations are rarely required and drug treatment is usually ineffective. Consistent follow up and a sympathetic physician forms the basis of management in patients with colic. There is a critical need for more evidence based treatment protocols.

\section{Competing interests}

The author declares that he has no competing interest.

Received: 16 January 2012 Accepted: 23 July 2012

Published: 23 July 2012

\section{References}

1. Wessel MA, Cobb JC, Jackson EB: Paroxysmal fussing in infancy, sometimes called "colic". Pediatr. 1954, 14:721.

2. Pauli-Pott U, Becker K, Mertesacker T, Beckmann D: Infants with "Colic"-mothers' perspectives on the crying problem. J Psychosom Res 2000, 48(2):125-132.

3. Roberts DM, et al: Infantile colic. Am Fam Physician 2004, 70:735.

4. Krugman RD: Child abuse and neglect Follow-up. Am J Dis Child 1 147:517.

5. Colic: The Merck Manuals: The Merck Manual for Healthcare Prof tonan http://www.merckmanuals.com/professional/sec19/ch266/c 566 fhtml. Accessed Feb. 28, 2011.

6. Savino F: Focus on infantile colic. Acta Paediatrica. 2007, 96:12

7. Clifford TJ, Campbell MK, Speechley KN, Gorodzin Ky F: Infant colic empirical evidence of the absence of an asso ation with source of early infant nutrition. Arch Pediatr Adolesc Med. 2002 56:1123-1128.

8. Illingworth RS: "Three months" colic. Arch Dis CA .954, 2 :165-174.

9. Barr RG: Colic and crying syndromes infants. Pearuencs 1998, 1025(suppl E):1282-1286.

10. Poole SR: The infant with acute, unexplc in d, e, essive crying. Pediatrics 1991, 88:450-455.

11. Harley LM: Fussing and ing ir loung in. ants. Clinical considerations and practical manaomen. Phila] 1969, 8:138-141.

12. Gupta SK: Is colic gastrointe al disorder? Curr Opin Pediatr 2002, 14:588-592.

13. White BP, Gun war Mis rson MC, Donzella B, Barr RG: Behavioral and physiolo, sal responsi sleep, and patterns of daily cortisol prody tion in infants win and without colic. Child Dev. 2000, 71:862-877.

14. Barr $R_{L}$.... ing ur understanding of infant colic. Arch Pediatr Adolesc Mad. 200. $6: 1172-1174$.

J. assa EL, own MJ: Maternal smoking and infantile gastrointestinal dy aulation: the case of colic. Pediatrics 2004, 114(4):e497-e505.

6. reenes $\triangle S$, Schutzman SA: Occult intracranial injury in infants. Ann Emerg 1998, 32:680-686.

17. Hi),emeier AC: Gastroesophageal reflux: diagnostic and therapeutic approaches. Pediatr Clin North Am. 1996, 43:197-212.

18. Orenstein SR, Shalaby TM, Cohn JF: Reflux symptoms in 100 normal infants: diagnostic validity of the infant gastroesophageal reflux questionnaire. Clin Pediatr (Phila). 1996, 35:607-614.

19. Weissbluth M: Colic. In Gellis \& Kagan's Current pediatric therapy. 16th edition. Edited by Burg FD, Gellis SS, Kagan BM. Philadelphia: Saunders; 1999:674-678

20. Forsyth BWC, MCCarthy PL, Leventhal JM: Problems of early infancy, formula changes, and mothers' beliefs about their infants. J Pediatr 1985, 106(6):1012-1017.
21. Levitzky S, Cooper R: Infant colic syndrome-maternal fantasies of aggression and infanticide. Clin Pediatr 2000, 39:395-400.

22. Metcalf $T$ J, Irons $T G$, Sher LD, Young PC: Simethicone in the treatment of infant colic: a randomized, placebo-controlled, multicenter trial. Pediatrics 1994, 94:29-34.

23. Lucassen PL, Assendelft WJ, Gubbels JW, van Eijk JT, van Geldrop WJ, Neven AK Effectiveness of treatments for infantile colic: systematic review [published erratum appears in BMJ 1998;317:171]. BMJ 1998, 316:1563-1569.

24. Savino F, Brondello C, Cresi F, Oggero R, Silvestro L: Cimetropi n birmide in the treatment of crisis in infantile colic. J Pediatr Gastroent 2002, 34:417-419.

25. American Academy of Pediatrics, Committee on Nutrí infant Formulas. Pediatrics 2000, 106:346-349.

26. Jakobsson I, Lindberg T: Cow's milk proteins car 2 infa colic in breast-fed infants: a double-blind crossove study. Pediat, 1983, 71:268-271.

27. Evans RW, et al: Maternal diet and infantil lic in breast-fed infants. Lancet 1981, 1:1340-1342.

28. Lucassen PL, et al: Infantile coli Cryin me reduction with a whey hydrolysate: a double-blind andomizea, cébo-controlled trial. Pediatrics 2000, 106:1349, 13

29. Hill DJ, Hudson IL, Sheffieid LJ, S, on MJ, Menahem S, Hosking CS: A low allergen diet is a cont interv con in infantile colic: Results of a community-bac d stuc .J Allergy Clin Immunol 1995, 96:886-892.

30. Hill DJ, Roy N, A, ifect of a low-allergen maternal diet on colic among breas infants: A randomized, controlled trial. Pediatrics 2005, 1 - $709-\mathrm{e} 715$.

31. Caffarelli $\rightarrow$ G Glordano S, Cavagni G: Anaphylaxis induced by exercise and relay,d to multiple food intake. Allergy Asthma Proc 1997, 18:245-248

Gaffarelli C, Nerzi V, Perrone F, Cavagni G: Food related, exercise induced vhylaxis. Arch Dis Child 1996, 75:141-144.

a 10 F, Pelle E, Palumeri E, Oggero R, Miniero R: Lactobacillus reuteri (A) nerican Type Culture Collection Strain 55730) versus simethicone in ne treatment of infantile colic: a prospective randomized study. Pediatrics 2007, 119(1):e124-e130.

34. Savino F, Cordisco L, Tarasco V, Palumeri E, Calabrese R, Oggero R: Lactobacillus reuteri DSM 17938 in infantile colic: a randomized, double-blind, placebo-controlled trial. Pediatrics 2010, 126(3):e526-e533.

35. Critch JN: Infantile colic: Is there a role for dietary interventions? Paediatr Child Health 2011, 16:47-49.

36. Akcam M, Yilmaz A: Oral hypertonic glucose solution in the treatment of infantile colic. Pediatr Int 2006, 48(2):125-127.

37. Weizman Z, Alkrinawi S, Goldfarb D, Bitran C: Efficacy of herbal tea preparation in infantile colic. J Pediatr 1993, 122:650-652.

38. Weizman Z, Aldrinawi S, Goldfarb D, Bitran C: Herbal teas for infantile colic [Letter; author reply]. J Pediatr 1993, 123:670.

39. Olafsdottir E, Forshei $\mathrm{S}$, Fluge G, Markestad T: Randomised controlled trial of infantile colic treated with chiropractic spinal manipulation. Arch Dis Child 2001, 84(2):138-141.

40. Wiberg JM, Nordsteen J, Nilsson N: The short-term effect of spinal manipulation in the treatment of infantile colic: a randomized controlled clinical trial with a blinded observer. J Manipulative Physiol Ther. 1999, 22(8):517-522.

41. van Sleuwen BE, et al: Swaddling: a systematic review. Pediatrics 2007, 120(4): Available at: www.pediatrics.org/cgi/content/full/120/4/e1097.

42. Gerard CM, et al: Physiologic studies on swaddling: an ancient child care practice, which may promote the supine position for infant sleep. J Pediatrics 2002, 141:398-403.

43. Brackbill Y, Adams SG, Crowell DH, et al: Arousal level in neonates and preschool children under continuous auditory stimulation. J of Exp Child Psychol 1966, 4:178-188.

44. Brackbill Y: Cumulative effects of continuous stimulation on arousal levels in infants. Child Dev 1971, 42:17-26.

45. van den Daele L: Modification of infant state by treatment in a rockerbox. J Psychol 1970, 74:161-165.

doi:10.1186/1824-7288-38-34

Cite this article as: Kheir: Retracted: Infantile colic, facts and fiction.

Italian Journal of Pediatrics 2012 38:34. 